\title{
Effects of a First Aid Coaching Program on First Aid Knowledge, Confidence, and Performance of Child Care Teachers
}

\author{
Juhee Lee ${ }^{1}$, Won-Oak $\mathrm{Oh}^{2}$ \\ ${ }^{1}$ College of Nursing, Graduate School of Korea University, Seoul; ${ }^{2}$ College of Nursing, Korea University, Seoul, Korea
}

Purpose: The purpose of this study was to develop a first aid coaching program (FACP) and to investigate its effects on the first aid knowledge, confidence, and performance of childcare teachers. Methods: A Delphi survey that included 16 experts was used to develop the FACP. A total of 60 participants were included to test the effectiveness of the program. The FACP developed using the survey results focused on improving first aid knowledge, confidence, and performance using a coaching-based method. First aid and cardiopulmonary resuscitation (CPR) performance was assessed using 39 items from the program content. Results: Using a 3-round Delphi survey, 6 areas and 42 detailed topics for group and individual coaching programs were developed. The knowledge scores were significantly higher in the experimental group than in the control group $(t=4.24, p=.001)$. The confidence scores were significantly higher in the experimental group than in the control group $(\mathrm{F}=3.89, p<.001)$. The performance scores were significantly higher in the experimental group than in the control group $(t=12.40, p<.001)$. Conclusion: Continuous application of the FACP among child care teachers is expected to minimize the harm caused by minor accidents at child care facilities. This program should be formally implemented on a consistent basis.

Key words: Health education, First aid, Coaching, Delphi technique

\section{Corresponding author Won-Oak Oh \\ https://orcid.org/0000-0003-0156-3422}

College of Nursing, Korea University,

145 Anam-ro, Seongbuk-gu, Seoul 02841, Korea

TEL +82-2-3290-4928 FAX +82-2-928-9108

E-MAIL wooh@korea.ac.kr

*This article was adapted from a thesis by Juhee Lee in partial fulfillment of the requirements for the master's degree at Korea University.

Received Jun 12, 2018 Revised Jun 26, 2018 Accepted Jul 2, 2018
(2) This is an Open Access article distributed under the terms of the Creative Commons Attribution NonCommercial License (http://creativecommons.org/licenses/by-nc/4.0/) which permits unrestricted non commercial use, distribution, and reproduction in any medium, provided the original work is properly cited.

\section{INTRODUCTION}

Social activities by women and increased early educational needs of children have increased the demand for child care facilities. In the United States, nearly 11 million children are cared for at child care centers, family child care homes, and non-parental in-home child care [1]. In South Korea, nearly $46 \%$ of infants and young children aged $0 \sim 6$ years are cared for at child care centers because the extended family structure of the past has deteriorated and changed into a small family structure [2]. In other words, child care facilities have grown beyond simply providing child care to becoming a second family living space for young children.

With the increase in the number of child care facilities for young children, a simultaneous increase in the number of safety accidents in these facilities is anticipated. According to a survey in Australia, $41 \%$ of kindergarten teachers, $28 \%$ of general child care teachers, and $13 \%$ of in-home child care teachers experienced safety accidents while working in child care [3]. The South Korea Consumer Agency [4] reported that accidents occurred about once or twice a year in $91.7 \%$ of child care facilities. Day care center accidents have increased from year to year and surged from 2,400 in 2014 to 6,700 -nearly 
three times higher- in 2015 [4].

Infants and young children are very inquisitive and impulsive, and they attempt to imitate others' behavior; however, their physical and cognitive abilities are not sufficiently developed to protect them from harm in an emergency [5]. The coping skills of child care teachers and their ability to take quick action in an emergency are extremely important because even a minor accident can present a threat to the health or even the life of an infant or a young child. Additionally, there may be accompanying economic losses [1]. However, although emergencies occur at child care centers, child care teachers, who are normally the first responders often lack even basic first aid training skills $[6,7]$.

In the United States and Australia, teachers who are trained to administer first aid are deployed at specific facilities [3]. However, in South Korea, only child care facilities that are responsible for more than 100 children are required to employ nurses or nursing assistants, in accordance with the Infant Care Act [8]. More than $95 \%$ of child care facilities do not meet the 100-children requirement [8]; therefore, these facilities have no choice but to rely on the competency of child care teachers to deal with safety accidents, as it is impossible to place qualified nursing professionals at each facility.

Based on the Infant Care Act in South Korea, child care teachers receive first aid training every 3 years; however, the annual number of hours of training is scant and more than half of the training comprises instructor-led lectures to a group [9]. Even if practical training is included, in most cases, it is limited to cardiopulmonary resuscitation (CPR) education. Education for other common first aid situations specific to infants and young children most often involves theoretical, instructorled lectures [9,10]. Consequently, within the current education system, there is a limit to the actual level of effective response that a day care teacher can provide in the event of a child care emergency. As mentioned above, at most child care centers there are no nurses on staff, meaning that is especially important for nurse health professionals to educate child care teachers because of the importance of teachers' coping skills in emergency situations.

According to some studies, even child care teachers who had received training in emergency management recognize their knowledge level as basic, and they still needed consistent support from experts, such as nurses or other health care providers $[11,12]$. Therefore, it is necessary to adopt supportive educational strategies for child care teachers that would enable them to build confidence in performing first aid. Recently, the method of coaching has been proposed as a learning strategy that is based on the needs of learners.

Unlike traditional consultants and mentors, coaching is a counselor-driven method for guiding a coachee, the direct, personal subject of coaching, in the right direction. Furthermore, coaching provides personal goal-directed advice to enhance learning effectiveness [13]. Coaching is not meant to help individuals directly; instead, it is a means of support to help them act on their own. The entire process involves interactive communication activities based on trust [14]. The most common coaching strategy model is the GROW (Goal, Reality, Options, Will) model [15]. The GROW model follows a common troubleshooting process that involves identifying the cause of the problem, finding a solution, and performing. This model is known to be a simple and useful approach that focuses on coachees' behavior during the coaching process and helps them achieve their goals [14-16]. Previous studies related to health care have reported that the coaching method was helpful for improving practical skill or health management abilities $[17,18]$. Therefore, the application of coaching to emergency management skills is expected to enhance child care teachers' confidence and ability to perform first aid.

The purpose of this study was to develop a first aid coaching program (FACP) for child care teachers using the Delphi method and to identify the effects of the FACP on child care teachers' knowledge, confidence, and performance of CPR and trauma-related emergency treatment.

\section{METHODS}

\section{Study Design and Sample}

This study used the Delphi survey method to develop the FACP. A non-equivalent control group pre-post design was then used to investigate the effects of the FACP (Figure 1).

\section{Developing the FACP}

In this study, 16 experts participated in FACP development through a Delphi survey panel. Delphi survey panels consist of highly educated professionals who have extensive handson experience. The participants of Delphi surveys should be carefully selected to represent a range of participants and professional expertise and to ensure the relevance, and integrity of participation [19]. Thus, the Delphi survey panels for this study were composed of child care and nursing professionals and practitioners who could provide practical information on first aid for infants and young children. A Delphi survey is generally developed by a number of panels consisting of about 15 to 35 experts each [20]. Therefore, 16 subjects from a Delphi survey panel matching the specified criteria were eligible to participate in this research: 2 pediatric nursing professors, 3 daycare directors, 6 child care teachers, and 5 emergency medical technicians. 


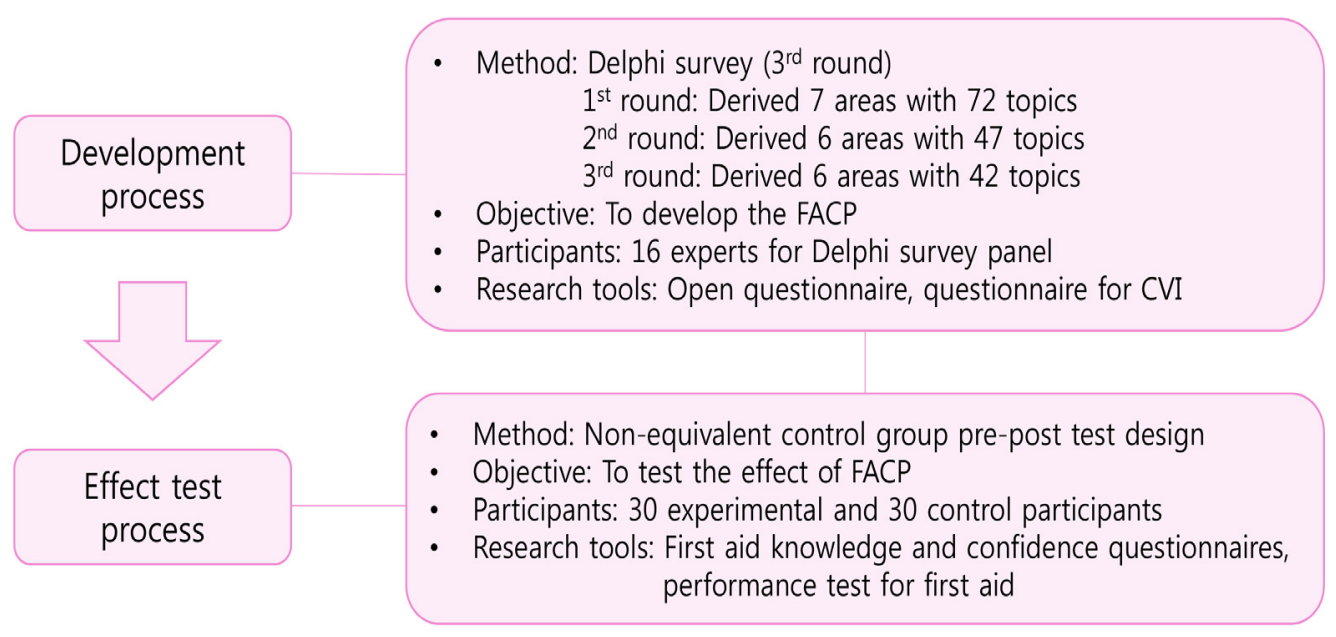

Figure 1. Study design and process. (FACP=First aid coaching program; CVI=Content validity index.)

\section{Data Collection Procedures of the Delphi Survey for De - veloping the FACP}

The Delphi survey was conducted a total of 3 times from October 1, 2015 to January 8, 2016. The survey proceeded from open-ended questions in the first round to structured questions in the second and third rounds. Based on previous studies and a literature review for the first-round Delphi survey, 7 areas were identified as important main topics related to first aid or emergency management that are necessary for child care teachers. These areas were: 1) first aid, including safety and emergency management methods; 2) safety-related characteristics of infants and young children; 3) emergency treatment of various situations that might occur; 4) caregivers' attitudes in emergency situations; 5) CPR; and 6) other areas in which caregivers expressed interest. The initial Delphi survey was conducted using an open-ended questionnaire to derive, without expert bias, divergent perceptions of the key elements that could be included in each topic. The second Delphi survey was administered to assess the appropriateness of the detailed content of the first aid topics selected in the first survey to identify those items with a content validity index (CVI) value greater than .75. The third Delphi survey was administered to the same panel of experts, who freely gave their opinions after reviewing the derived detailed content derived from the second survey that would be used to train child care teachers. The researchers determined whether the included educational topics, methods, and implementation were sufficiently practical and appropriate.

\section{Testing the Effects of the FACP}

Child care teachers who had 1 or more year of work experi- ence at 4 child care centers with more than 40 children were recruited. The reason for recruiting child care teachers with more than 1 year of experience was that they can work independently as a child care teacher starting 1 year after beginning work as a childcare teacher [21].

The centers were located in the cities of Suwon and Yongin in Gyeonggi Province, South Korea. The child care teachers at the 2 centers in Suwon were selected as a control group, while the teachers at the 2 centers in Yongin comprised the experimental group. G*Power 3.1 was used to compute the sample size. To calculate the effect size for the present study, we followed a procedure similar to that used in previous research targeting small groups who received CPR and first aid educa-

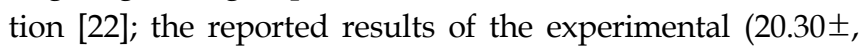
$0.81)$ and control groups $(10.77 \pm 1.41)$ were used for computation. Consequently, the effect size was $\mathrm{d}=8.29$, and the number of participants required for the experimental and control groups was calculated as 8 people each. Following this calculation (significance level $[\alpha]=.05$, power $[1-\beta]=.80$, effect size $[\mathrm{d}]=.80$ with the independent-sample t-test, using the $\mathrm{G}^{*}$ Power program), the minimum indicated sample size for each group was 26 . However, assuming a 20 30\% dropout rate and based on the dataset, we determined that a minimum of 30 participants would be required for the experimental intervention study [23]. Thus, 34 people each were selected for the experimental group and the control group. A total of 60 participants were included in the final dataset: 30 who received the experimental program versus 30 controls. In the experimental group, 4 participants were excluded from the final data analysis because they did not attend coaching sessions more than twice, and 4 participants in the control group were also excluded because they could not complete the post-test for personal reasons. 


\section{Measurement Tools}

First, knowledge of CPR and trauma-related emergency treatment was measured using the Emergency and Administering First Aid in Day-care Centers and the Small Group Learning Guide for Emergency Situations [9,22]. Researchers realigned those methods using references and used a total of 20 questions for the measurement. Each question had 4 answer choices, only 1 of which was correct. Each correct answer received 1 point, and no points were given for an incorrect answer. Once content validity was professionally certified by 2 medical doctors, the questionnaire was completed. The value of the Kuder-Richardson Formula 20 (KR-20) reliability coefficient was .72 in this study.

Second, the researchers designed 16 items that were judged to be sufficiently representative of the details from the Delphi survey, to measure participants' confidence regarding to CPR and trauma-related first aid. The detailed content was as follows: emergency situation management, first aid for a high fever and febrile seizure, first aid for vomiting, closed/open wound treatment, emergency treatment for contusion, first aid for a sprain/fracture/dislocation, emergency treatment for removal of foreign bodies from the ear and nose, emergency management of thermal burns, emergency treatment of damaged or broken teeth, first aid for bleeding from a head wound, first aid for food lodged in the throat, CPR, and use of an automated external defibrillator. Each content area was measured using a 5-point Likert scale, with 5 points for "very confident" and 1 point for "not confident". After content validity was verified by 2 nursing professors, the researchers modified the questions to fit the survey format. The Cronbach's $\alpha$, indicating reliability, was .74 in this study.

Third, trauma emergency management and CPR capability were measured through direct performance evaluation by research assistants. A total of 39 items were selected from the validated content of the education program: 8 items for CPR, 6 items for bruises/dislocations, 5 items for abrasions, 6 items for high fever, 9 items for febrile convulsion, and 5 items for sprains/fractures. If participants correctly performed first aid in each direct emergency, they received 1 point; participants received 0 points if they could not correctly perform the task. After verifying the content validity with 2 professors, researchers modified and finalized the survey checklist. The KR-20 value was .76 in this study.

\section{FACP Intervention and Data Collection Procedures}

The pre-test questionnaire included items on the general characteristics of the participants, their knowledge of trauma first aid and CPR, and their confidence regarding trauma first aid and CPR, before they received training through the FACP. The FACP was conducted by the researchers and research assistants. The Researchers had more than 7 years of experience with child care in a university hospital, had worked for more than 3 years as a health care nurse at a day care center, and had provided first aid training for children and child care teachers. The research assistants were 2 health care nurses at day care centers and 2 basic life support (BLS)-certified emergency medical technicians. The researchers and the research assistants underwent 4 training sessions to equalize their degree of expertise. The main content of the training was the procedure and method of each first-aid treatment. We conducted a virtual evaluation to confirm the consistency of evaluations between the researchers and the research assistants.

During the experimental intervention, all participants were included in a CPR and emergency treatment group coaching program consisting of 8 coaching sessions, as well as a telephone-based or individualized coaching program the following day, each also consisting of 8 coaching sessions. The first aid and CPR capabilities of participants were tested in a follow-up assessment, after completion of the 8 coaching sessions. The control group received traditional teacher-centered instruction. The FACP was administered to participants in the experimental group according to the GROW coaching model [15]. The 40-minute group coaching program was based on sections of content that participants did not understand or where insufficient information was provided. In the group coaching, we set up and confirmed detailed goals that the subjects wanted to achieve in each topic in G (goal setting) stage before the start of instruction on a given topic in the FACP. In the $\mathrm{R}$ (reality) stage, we identified difficulties and obstacles to practical application of the first aid topic through coaching questions. In the $\mathrm{O}$ (options) stage, we provided motivation for education by talking about what to know and do about each first aid topic, and carried out coaching sessions based on participants' need. In the last stage of W (will), we confirmed the content and encouraged participants to practice in their workplace with confidence.

In all group coaching sessions, demonstrations and practice were included in all areas except for safety accidents at day care facilities (area 1) and first aid considerations according to child development (area 2). The practice sessions consisted mainly of general coping strategies during an emergency (e.g. making a 911 call), fever management, febrile seizure, injury (lacerations, fractures, burns, etc.), suffocation, CPR, and so on. These areas of study were the topics identified during FACP development.

Individualized coaching is a method in which a researcher conducts coaching by telephone or by visiting the participants directly, from the day after group coaching to the day before 
the next group coaching sessions. The individualized coaching sessions took approximately 20 minutes and were based on each participant's desire to receive more specific information on a topic covered in the group session.

For the control group, theories about first aid treatment were presented using only the lecture method. The post-test was conducted 3 weeks after the experimental intervention. Only experimental group participants were tested to assess their ability to provide emergency treatment and CPR.

\section{Data Analysis}

The data were analyzed with SPSS for Windows version 16.0 and the $x^{2}$ test was used to test the homogeneity of the general characteristics of participants. The independent t-test, paired t-test, and analysis of covariance (ANCOVA) were used to test the hypotheses.

\section{Ethical Considerations}

This research was conducted after an Institutional Review Board approval was received from Korea University (1040548KU-IRB-15-143-A-1). The child care facility directors in the cities of Suwon and Yongin agreed to cooperate with the study. The researchers described the purpose and methods of the study to all participants and explained that participants could withdraw at any time without any type of penalty or disadvantage. Participants were also informed that the anonymity and confidentiality of the collected participant data used in the research were guaranteed and that the results would not be used for purposes other than the study.

\section{RESULTS}

\section{Development of the FACP}

In the first-round Delphi survey, 72 detailed topics were derived and grouped into 7 groups created from the 6 area based on our analysis of the content. The area of "understanding of safety and first aid" was further divided into 2 areas: accidents in a child care facility and the meaning of first aid and training.

In the second Delphi survey, the CVI was calculated for questions with a high probability of use. After identifying topics with a CVI value greater than $.75,25$ topics from the initial total of 72 were deleted, and the remaining of 45 topics were grouped into 6 areas.

In the third-round Delphi survey, 5 detailed topics were excluded because they differed from the developed curriculum or the opinions compiled from the panels. In other words, questions were removed if they were impractical to implement in a coaching session or were of lower priority. Thus, after a final discussion with the experts, 42 detailed topics in 6 areas were selected for the trauma-related first aid and CPR educational program. Most experts suggested adding individual coaching to resolve concerns arising after the group coaching sessions. Consequently, the FACP developed in this study included 6 areas (safety accidents at day care facilities, first aid considerations according to child development, meaning of first aid and education, child care teachers' actions in emergency situations, first aid in various situations, and CPR) and 42 detailed topics for group coaching and individual coaching sessions. The final FACP was implemented among child care teachers by a trained child care nurse (Figure 1).

\section{Effects of the FACP}

\section{1) Subjects' demographic characteristics and homogeneity test}

The average age of participants in the experimental group was $27.11 \pm 3.21$ years and $26.92 \pm 4.32$ years in the control group. Their average work experience was $4.13 \pm 2.14$ years in the experimental group and $3.89 \pm 1.92$ years in the control group (Table 1).

The homogeneity test revealed no significant differences in general characteristics between the 2 groups (Table 2). The results of the homogeneity test for first aid knowledge of the experimental and control groups showed that there was no significant difference between the groups $(t=0.13, p=.895)$. However, there appeared to be a significant difference in the degree of first aid confidence, which was not homogeneous $(\mathrm{t}=$ $3.89, p<.001$ ) (Table 2).

\section{2) Hypothesis test}

There were significant differences in pre-post knowledge scores between the experimental $(5.17 \pm 1.66)$ and control groups (3.20 \pm 1.19$)$. The knowledge scores were significantly higher compared in the experimental group than in the control group $(\mathrm{t}=4.24, p=.001)$ (Table 3).

The researchers analyzed the differences in the confidence score of the experimental and control groups before implementation of the FACP; however, the results did not appear homogeneous, so ANCOVA was conducted with the pre-confidence score as the covariate. The confidence scores were significantly higher in the experimental group than in the control group $(\mathrm{F}=3.89, p<.001)$ (Table 3$)$.

Participants in the experimental group who received the intervention showed a 10.20 4 4.51-point increase in the performance score, which was statistically significant $(t=12.40, p<$ .001). Additionally, all performance scores for the coaching areas were significantly higher in the experimental group than 
Table 1. General Characteristics of Participants and Homogeneity Test

$(N=60)$

\begin{tabular}{|c|c|c|c|c|c|}
\hline \multirow{2}{*}{ Variables } & \multirow{2}{*}{ Categories } & Exp. $(n=30)$ & Cont. $(n=30)$ & \multirow{2}{*}{$x^{2}$} & \multirow{2}{*}{$p$} \\
\hline & & $\mathrm{n}(\%)$ or $\mathrm{M} \pm \mathrm{SD}$ & $\mathrm{n}(\%)$ or $\mathrm{M} \pm \mathrm{SD}$ & & \\
\hline \multirow{5}{*}{ Age (year) } & $20 \sim 25$ & $14(46.6)$ & $10(33.3)$ & \multirow{5}{*}{10.89} & \multirow[t]{5}{*}{.092} \\
\hline & $26 \sim 30$ & $11(36.7)$ & $11(36.7)$ & & \\
\hline & $31 \sim 35$ & - & $8(26.7)$ & & \\
\hline & $36 \sim 40$ & $5(16.7)$ & $1(3.3)$ & & \\
\hline & & $27.11 \pm 3.21$ & $26.92 \pm 4.32$ & & \\
\hline \multirow{3}{*}{ Education level } & College & $8(26.7)$ & $6(20.0)$ & \multirow[t]{3}{*}{5.29} & \multirow[t]{3}{*}{.259} \\
\hline & University & $19(63.3)$ & $22(73.3)$ & & \\
\hline & Above master & $3(10.0)$ & $2(6.7)$ & & \\
\hline \multirow[t]{5}{*}{ Work experience (year) } & $1 \sim 2$ & $11(36.7)$ & $11(36.7)$ & \multirow[t]{5}{*}{8.83} & \multirow[t]{5}{*}{.718} \\
\hline & $3 \sim 5$ & $12(40.0)$ & $12(40.0)$ & & \\
\hline & $6 \sim 8$ & $5(16.7)$ & $5(16.7)$ & & \\
\hline & $\geq 9$ & $2(6.6)$ & $2(6.6)$ & & \\
\hline & & $4.13 \pm 2.14$ & $3.89 \pm 1.92$ & & \\
\hline \multirow[t]{4}{*}{ First aid-related courses ${ }^{\star \dagger}$} & First aid & $5(14.3)$ & $13(24.1)$ & \multirow[t]{4}{*}{7.70} & \multirow[t]{4}{*}{.957} \\
\hline & Health education & $10(28.6)$ & $18(33.3)$ & & \\
\hline & Safety education & $8(22.9)$ & $12(22.2)$ & & \\
\hline & Health and safety & $12(34.2)$ & $11(20.4)$ & & \\
\hline \multirow[t]{2}{*}{ First aid training by priority* } & Required & $29(96.7)$ & $28(93.4)$ & \multirow[t]{2}{*}{0.07} & \multirow[t]{2}{*}{.988} \\
\hline & Not required & $1(3.3)$ & $2(6.6)$ & & \\
\hline
\end{tabular}

${ }^{*}$ Fisher exact test; ${ }^{\dagger}$ Multiple-choice; Exp.=Experimental group; Cont.=Control group.

Table 2. Homogeneity Test for Dependent Variables

\begin{tabular}{|c|c|c|c|c|}
\hline \multirow{2}{*}{ Variables } & Exp. $(n=30)$ & Cont. $(n=30)$ & \multirow{2}{*}{$\mathrm{t}$} & \multirow{2}{*}{$p$} \\
\hline & $\mathrm{M} \pm \mathrm{SD}$ & $\mathrm{M} \pm \mathrm{SD}$ & & \\
\hline First aid knowledge & $12.63 \pm 1.67$ & $12.70 \pm 2.18$ & 0.13 & .895 \\
\hline First aid confidence & $40.47 \pm 3.45$ & $43.97 \pm 3.52$ & 3.89 & $<.001$ \\
\hline
\end{tabular}

Exp.=Experimental group; Cont. $=$ Control group.

Table 3. Effects of the First Aid Coaching Program on First Aid Knowledge and Confidence

$(N=60)$

\begin{tabular}{|c|c|c|c|c|c|c|}
\hline \multirow{2}{*}{ Variables } & \multirow{2}{*}{ Group } & Pre & Post & Difference & \multirow{2}{*}{ tor $F$} & \multirow{2}{*}{$p$} \\
\hline & & $\mathrm{M} \pm \mathrm{SD}$ & $\mathrm{M} \pm \mathrm{SD}$ & $\mathrm{M} \pm \mathrm{SD}$ & & \\
\hline \multirow[t]{2}{*}{ First aid knowledge } & Exp. $(n=30)$ & $12.63 \pm 1.67$ & $17.80 \pm 0.81$ & $5.17 \pm 1.66$ & \multirow[t]{2}{*}{4.24} & \multirow[t]{2}{*}{.001} \\
\hline & Cont. $(n=30)$ & $12.70 \pm 2.18$ & $15.90 \pm 1.32$ & $3.20 \pm 1.19$ & & \\
\hline \multirow[t]{2}{*}{ First aid confidence* } & Exp. $(n=30)$ & $40.47 \pm 3.45$ & $54.33 \pm 2.68$ & $13.86 \pm 3.79$ & \multirow[t]{2}{*}{3.89} & \multirow[t]{2}{*}{$<.001$} \\
\hline & Cont. $(n=30)$ & $40.47 \pm 3.45$ & $56.90 \pm 4.81$ & $12.93 \pm 4.89$ & & \\
\hline
\end{tabular}

*ANCOVA with the pre-confidence score as a covariate; Exp.=Experimental group; Cont.=Control group.

in the control group $(\mathrm{t}=3.92 \sim 9.28, p<.001)$ (Table 4).

\section{DISCUSSION}

The Delphi survey identified the following 6 areas: safety accidents in day care facilities, first aid considerations according to child development, meaning of first aid and education, child care teachers' actions in emergency situations, first aid in various situations, and CPR. Compared with existing pro- grams that are tailored to general emergency management training, the FACP developed in this study was distinct in that it focused on the contextual features of first aid and CPR. These differences are as follows. The FACP differed from other programs in area 1 by including "safety accidents in child care" in the definition of safety accidents, emphasizing the importance and causes of general accidents in child care, and incorporating educational programs about these topics. We found that emphasizing the above definition and the fact that 
Table 4. Effects of the First Aid Coaching Program on First Aid Performance

\begin{tabular}{|c|c|c|c|c|c|c|}
\hline \multirow{3}{*}{ Variables } & \multirow{3}{*}{ Range } & \multicolumn{3}{|c|}{ Experimental group $(n=30)$} & \multirow{3}{*}{$\mathrm{t}$} & \multirow{3}{*}{$p$} \\
\hline & & Pre & Post & Difference & & \\
\hline & & $\mathrm{M} \pm \mathrm{SD}$ & $\mathrm{M} \pm \mathrm{SD}$ & $\mathrm{M} \pm \mathrm{SD}$ & & \\
\hline $\mathrm{CPR}$ & $0 \sim 8$ & $5.50 \pm 1.17$ & $6.90 \pm 1.40$ & $1.40 \pm 1.96$ & 3.92 & $<.001$ \\
\hline Bruise/dislocation & $0 \sim 6$ & $3.10 \pm 0.80$ & $4.90 \pm 0.76$ & $1.80 \pm 1.24$ & 7.93 & $<.001$ \\
\hline Abrasion & $0 \sim 5$ & $2.90 \pm 0.71$ & $4.53 \pm 0.63$ & $1.63 \pm 0.96$ & 9.28 & $<.001$ \\
\hline High fever & $0 \sim 6$ & $3.80 \pm 0.85$ & $5.23 \pm 0.63$ & $1.43 \pm 1.01$ & 7.80 & $<.001$ \\
\hline Febrile convulsion & $0 \sim 9$ & $5.00 \pm 1.37$ & $7.80 \pm 0.89$ & $2.80 \pm 1.86$ & 8.23 & $<.001$ \\
\hline Sprain/fracture & $0 \sim 5$ & $3.20 \pm 0.61$ & $4.33 \pm 0.48$ & $1.13 \pm 0.78$ & 8.00 & $<.001$ \\
\hline Total average & $0 \sim 39$ & $23.50 \pm 3.45$ & $33.70 \pm 1.84$ & $10.20 \pm 4.51$ & 12.40 & $<.001$ \\
\hline
\end{tabular}

$\mathrm{CPR}=$ Cardiopulmonary resuscitation.

most safety accidents can be prevented, as well as describing the current status of safety in child care were very effective for encouraging child care teachers to participate in the FACP program.

In area 2, the topic "first aid based on the phase of child development" was differentiated by presenting possible types of accidents specifically for each developmental stage; additionally, coaching was used here. Although child care teachers have a solid understanding of the developmental stages of children, they have less understanding of how the characteristics of each stage relate to the causes and prevention of accidents [9]. Therefore, area 2 is expected to contribute to the establishment of coping strategies for the prevention of safety accidents depending on the developmental stage of children. Additionally, area 3 was differentiated from the traditional education method by providing details about information that day care teachers, as non-health care practitioners, should relay to emergency workers and health care providers. The topic “child care teachers' management skills in emergency situations" in area 4 emphasized how child care teachers should communicate and systematically handle real emergency situations. Setting initial priorities in emergency settings and determining how to share roles can directly affect patients' lives and are critically important factors for preventing complications.

In the FACP developed in the present study, group and individual coaching were applied based on the results of the Delphi survey. Group coaching has the advantage of not only reducing costs but also involving group dynamics, which are not used in individual coaching [24]. However, individual coaching can facilitate effective learning by providing suitable feedback to the individual with a one-on-one focus on the specific needs and capabilities of that person [25]. In particular, individual coaching is necessary when implementing a program where each individual child care teacher is at a different level. Thus, it can be concluded that simultaneously implementing group and individual coaching in the FACP contributed to improvement in the first aid competency child care teachers in our study.

The FACP was found to be effective in promoting knowledge, confidence, and performance of first aid and CPR. Participants in the experimental group demonstrated greater improvements in their knowledge of trauma-related first aid and CPR than did those in the control group. These findings are consistent with previous work, which concluded that emergency management training for child care teachers contributed to improvements in knowledge $[10,26]$. Considering that advancements in knowledge are fundamental to inducing changes in human behavior, improving knowledge about first aid is essential for teachers to be able to perform the necessary skills in this area. These results indicate that providing feedback through group and individual coaching contributed to improvements in first aid knowledge.

The FACP also improved confidence related to emergency management skills, as the corresponding score in the experimental group was higher than that in the control group. According to a previous study, a group coaching program yielded improvements in the self-efficacy of nursing professionals by extending their self-awareness through a process of selfchange [26]. Moreover, the results of this study support the finding that a coaching program contributed to improving the work confidence of neonatal nurses [18]. Coaching is a process that facilitates self-growth and provides information and skills to awaken the trainee's own potential abilities [15]. The continuous feedback provided for each measurement in this coaching program may have contributed to enhancing confidence among child care teachers regarding their ability to provide first aid.

Finally, this research provides evidence that the FACP contributed to improving first aid performance in the experi- 
mental group. Trainees showed significant improvements $(\sim 43 \%)$ in their performance, which improve from a previous average score of 23.50 to an average of 33.70 in each performance capability test. Since coaching is goal-oriented and focuses on the issues currently facing a learner, it has the advantage of helping to motivate participants' creativity and their own unique solutions $[27,28]$. In particular, the FACP developed in this study though to have been effective in enhancing child care teachers' performance on the basis of the GROW coaching model, through a process that included goal setting, understanding reality, searching for options, and confirming intent in all areas. Allen et al. [17] found that patients with various chronic diseases experienced improvements in their motivation for self-management through an e-coaching program conducted via the Internet. Miyamoto et al. [29] recently developed a mobile coaching method to improve self-confidence in health care for diabetic patients. Therefore, we suggest considering the implementation of FACP using a mobile app or an internet-based interface in the future.

This study has several strengths compared with previous studies. First, whereas existing educational programs intended for child care teacher are only taught through instructorled training sessions, the FACP used a method of individual coaching in which feedback was provided for each subject area based on the needs of the learner, as well as group coaching for each topic. Second, the FACP included not only CPR, but also practical education in trauma-related first aid. Third, this study developed the FACP in a way that would maximize its value, as it was not based on a simple database; instead, the Delphi approach was applied with emergency-related experts and on-site child care professionals. The Delphi approach has the advantage of eliminating elements that are outside the scope of the main topics and deriving results focused on the most essential elements, as experts arrive at a final consensus by suggesting their opinions and coordinating their perspectives $[27,30]$.

This study also has some limitations. The performance evaluation in the study (the last dependent variable) was only conducted among participants in the experimental group, to assess the generalizability of the results. Therefore, to improve the internal validity of the FACP, we suggest using a control group with this variable for comparisons in future work. Second, as the post-evaluation was performed only once at the completion of the FACP, data about the ongoing effects of the program are lacking. Since effectiveness increases when first aid coaching is continuous and repeated, the researchers propose long-term implementation of the FACP accompanied by an evaluation of the duration of its effectiveness. Third, the confidence scores were a dependent variable that did not show homogeneity. Although the appropriate statistical correction was made, the statistical sensitivity was lowered. Therefore, it is suggested that verification should be performed in future studies after ensuring homogeneity.

\section{CONCLUSION}

This study was conducted to develop an FACP for improving emergency coping skills among child care teachers and to determine the effectiveness of the program. The 6 areas in the FACP addressed not only responses to simple first aid situations but also included a definition of safety accidents, an approach based on the developmental phases of children, and emergency measures to help child care teachers cope effectively when confronted with emergency situations. Additionally, the coaching approach based on the GROW model contributed to improvements in practice capability and confidence regarding first aid performance among child care teachers, as well as enhanced knowledge about first aid.

\section{Conflict of interest}

No potential or any existing conflict of interest relevant to this article was reported.

\section{REFERENCES}

1. Childcare Aware of America. Child facilities and severe injuries in child care centers and family child care homes in America [Internet]. Arlington: Childcare Aware of America; 2014 [cited 2015 May 30]. Available from:

https://usa.childcareaware.org/wp-content/uploads/2015/10/ one-pager_-_child_fatalities_and_severe_injuries_-_june_2014.pdf.

2. South Korea Ministry of Health and Welfare. Day care statistics 2015 [Internet]. Seoul: South Korea Ministry of Health and Welfare; 2016 [cited 2016 September 19]. Available from:

http://www.kicce.re.kr/kor/publication/04_04.jsp?mode=view $\& i d x=19712 \&$ startPage $=0 \&$ listNo=91\&code $=$ etc04\&search_item $=$ \&search_order=\&order_list $=10 \&$ list_scale $=10 \&$ view_level $=0$.

3. McGrath BJ, Huntington AD. The health and wellbeing of adults working in early childhood education. Australian Journal of Early Childhood. 2007;32(3):33-38.

4. South Korea Consumer Agency. Investigation of safety accident patterns of children 2015 [Internet]. Seoul: South Korea Consumer Agency; 2016 [cited 2016 June 21]. Available from:

http://www.ciss.go.kr/children/selectBbsNttView.do?key=506 \&bbsNo=101\&nttNo=30483\&searchCtgry=\&searchCnd=SJ\&sear chKrwd=\%EC\%95\%88\%EC\%A0\%84\%EC\%82\%AC\%EA \%B3\%A0 \&pageIndex=1\&pageUnit=10\&integrDeptCode $=$.

5. Berk LE. Development through the lifespan. 6th ed. Boston: Pearson Education; 2013. p. 214-242. 
6. Rho SG. A study on the basic emergency treatment awareness level of kindergarten teacher - Focus on the Jeonbuk metropolitan area. Journal of Korean Institute of Fire Science and Engineering. 2007; 21(2):105-110.

7. Yoon S. A study on teachers' experiences of accidents in early childhood educational institutes. Early Childhood Education and Care. 2012;7(2):103-124.

8. South Korea Ministry of Health and Welfare. Day care statistics 2017 [Internet]. Seoul: South Korea Ministry of Health and Welfare; 2017 [cited 2018 March 17]. Available from: https://central.childcare.go.kr/ccef/community/data/DataSl.jsp ?BBSGB=40\&flag=SI\&BID=65925.

9. Lee JS. Teacher's abilities: Emergency and administering first aid in daycare center [master's thesis]. Seoul: Hankuk University; 2012. p. 1-61.

10. Hong C. The state of safety education of the baby and infant education institutions and the teachers' understanding of the countermeasures against safety accidents [master's thesis]. Incheon: Incheon National University; 2015. p. 1-76.

11. Oh K, Sim MK, Choi EK. Knowledge, self-confidence and practice of teachers concerning health and safety of children in child-daycare centers. Journal of Korean Academy of Child Health Nursing. 2008;14(2):155-162.

12. Hwang JY, Oh ES, Cho KJ. A study on the self-confidence in performance and education demand of first aid in kindergarten and daycare center teachers. Journal of the Korea Academia-Industrial cooperation Society. 2016;17(1):234-243.

https://doi.org/10.5762/KAIS.2016.17.1.234

13. International Coach Federation. Definition of coaching [Internet]. Kenturky: International Coach Federation; 2014 [cited 2015 May 13]. Available from:

http://www.coachfederation.org//For+Coaching+Clients/What +is+ICF.

14. Baek M, Jang KS. Development and verification on the effectiveness of coaching program for nurses. Journal of Health Informatics and Statistics. 2016;41(1):57-66.

https://doi.org/10.21032/jhis.2016.41.1.57

15. Whitmore SJ. Coaching for performance: GROWing people, performance and purpose. 3rd ed. London: Nicholas Brealey Publishing; 2002. p. 78-123.

16. Passmore J. An integrative model for executive coaching. Consulting Psychology Journal: Practice and Research. 2007;59(1):68-78. http://dx.doi.org/10.1037/1065-9293.59.1.68

17. Allen M, Iezzoni LI, Huang A, Huang L, Leveille SG. Improving patient-clinician communication about chronic conditions: Description of an internet-based nurse E-coach intervention. Nursing Research. 2008;57(2):107-112. https://doi.org/10.1097/01.NNR.0000313478.47379.98

18. Ammentorp J, Kofoed PE. Coach training can improve the self-efficacy of neonatal nurses. A pilot study. Patient Education and Coun- seling. 2010;79(2):258-261. https://doi.org/10.1016/j.pec.2009.08.015

19. Lee DY. The exploration of the evaluation standards for teaching competency of elementary school teachers applied via Delphi \& AHP. The Journal of Elementary Education. 2015;28(4):219-239.

20. Glenn JC, Gorden TJ. Futures research methodology [CD-Rom]. Version 2.0. Washington DC: American Council for the United Nations University, the Millennium Project; 2003. 1 CD-ROM: sound, color, $43 / 4$ in.

21. Paquet NL, Bocala C, Fronius T, Philllips D. The characteristics and experiences of beginning teachers in seven Northeast and Islands region states and nationally [Internet]. Washington DC: Regional Educational Laboratory At Education Development Center, Inc.; 2012 [cited 2016 Feb 18]. Available from:

https://www.wested.org/wp-content/uploads/2016/11/137237 2726resource1215-3.pdf.

22. Choi EJ. Effects of case-based small group learning on daycare center teachers' coping ability in emergency situations: Focus on daily life and cardiopulmonary resuscitation. Child Health Nursing Research. 2013;19(3):168-176. https://doi.org/10.4094/chnr.2013.19.3.168

23. Polit DF, Beck CT, Owen SV. Is the CVI an acceptable indicator of content validity? Appraisal and recommendations. Research in Nursing and Health. 2007;30(4):459-467.

https://doi.org/10.1002/nur.20199

24. Lee KJ, Do MH. The Effectiveness of the child sexual violence prevention coaching programs for children into the children's sexual konwledge and the ability of coping with sexual matters and violences. Korean Journal of Parent Education. 2011;8(1):45-67.

25. Han HJ. A study on managerial coaching competency required for line manager [master's thesis]. Seoul: Seoul National University; 2007. p. 1-110.

26. Yang EY, Kim IO. The Korea Academia-Industrial cooperation Society. Journal of Korea Academia-Industrial cooperation Society. 2014;15(6):3648-3657.

https://doi.org/10.5762/KAIS.2014.15.6.3648

27. Lee SG. The effects of group coaching on emotional intelligence and self-efficacy of the nurses. Journal of Korean Coaching Research. 2008;1(1):65-85.

28. Quirk M, Mazor K, Haley HL, Philbin M, Fischer M, Sullivan K, et al. How patients perceive a doctor's caring attitude. Patient Education and Counselling. 2008;72(3):359-366. https://doi.org/10.1016/j.pec.2008.05.022

29. Miyamoto S, Dharmar M, Fazio S, Tang-Feldman Y, Young HM. mHealth technology and nurse health coaching to improve health in diabetes: Protocol for a randomized controlled trial. JMIR Research Protocols. 2018;7(2):e45. https://doi.org/10.2196/resprot.9168

30. Lee JS. Delphi Method. 2nd ed. Seoul: Education \& Science; 2006. p. 23-28. 